\title{
The Fallacy of Beneficial Ignorance: A Test of Hirschman's Hiding Hand
}

\author{
Version 5.2 \\ Bent Flyvbjerg* \\ Accepted for publication in World Development
}

\begin{abstract}
Albert O. Hirschman's principle of the Hiding Hand stands stronger and more celebrated today than ever. The principle states that ignorance is good in planning, because if decision makers knew the real costs and difficulties of projects, few ventures would ever get started. The paper presents the first systematic test of the principle of the Hiding Hand, including a test of whether Hirschman's theory may be replicated with more and better data. This was found not to be the case. First, statistical tests reject the principle of the Hiding Hand at an overwhelmingly high level of significance $(\mathrm{p}<0.0001)$. In reality, the exact opposite happens of what the principle states: Instead of project success being secured by "creative error" and "beneficial ignorance" - where higher-than-estimated costs are outweighed by even higher-than-estimated benefits - the average project is in fact undermined by a double whammy of substantial cost overruns compounded by substantial benefit shortfalls. Second, Hirschman was found to have made the error of sampling on the dependent variable, undermining the validity of his findings. Third, Hirschman's sample of projects, on which he built his principle, is too small to support his wide conclusions. Fourth, Hirschman misrepresented his findings and misled his readers. In sum, the data do not support Hirschman's proposition that ignorance is good in planning. Ignorance is bad, if by bad we mean that ignorance leads to starting projects that should not have been started. Finally, the data also do not support an interpretation of Hirschman as an early behavioral economist, as proposed by Sunstein. Hirschman was a victim, not a student, of bias.
\end{abstract}

Keywords: Albert O. Hirschman; the principle of the Hiding Hand; ignorance; behavioral economics; management; development.

\footnotetext{
* Bent Flyvbjerg is the BT Professor and Chair of Major Programme Management at Oxford University's Saïd Business School.
} 


\section{Why the Hiding Hand Is Important}

Recently, when San Francisco's new Transbay Terminal megaproject - a multi-billion-dollar transit and real estate development scheme - incurred hundreds of millions of dollars in cost overruns, Willie Brown, former California State Assembly Speaker and Mayor of San Francisco, tried to calm the public with these words in The San Francisco Chronicle:

"News that the Transbay Terminal is something like $\$ 300$ million over budget should not come as a shock to anyone. We always knew the initial estimate was way under the real cost. Just like we never had a real cost for the [San Francisco] Central Subway or the [San Francisco-Oakland] Bay Bridge or any other massive construction project. So get off it. In the world of civic projects, the first budget is really just a down payment. If people knew the real cost from the start, nothing would ever be approved. The idea is to get going. Start digging” (Brown 2013).

Willie Brown here expresses the essence of Albert O. Hirschman's principle of the Hiding Hand:

If people knew the real costs and difficulties from the start, nothing would ever be approved. Therefore it is good they don't know, because we need to get things going, to start digging.

This view is also the oldest and most common justification of why low-balled cost estimates and optimistic business cases are considered acceptable in large projects (Flyvbjerg 2009). Following this idea, a certain amount of ignorance is desirable when beginning new projects, because without it projects would not get started. And starting projects is good, according to both Hirschman and Brown. Hirschman talked about "providential ignorance" (Alacevich 2014: 157). Here we call it "beneficial ignorance."

It has been almost 50 years since Hirschman's principle of the Hiding Hand was first published, and the theory today stands stronger than ever. ${ }^{1}$ It was recently republished as a Brookings Classic (Hirschman 2015) and celebrated by people like Cass Sunstein, Harvard Professor and administrator in the Obama White House, and Malcolm Gladwell, best-selling author and staff writer at The New Yorker (Sunstein 2015a, Gladwell 2013). The impact of the principle in the academy, policy, and practice is undisputed. And as more and bigger projects are built around the world in what has been dubbed the "biggest investment boom in history," the principle is 
becoming increasingly consequential in justifying rapidly growing project portfolios (Flyvbjerg 2014a). ${ }^{2}$ Below it will be argued, however, that the principle of the Hiding Hand is popular because it is politically convenient, and not because it is valid as an explanation of human behavior. We will see that instead of Hirschman's benevolent Hiding Hand, a malevolent Hiding Hand is typically at play. Hirschman's principle is popular because it gives theoretical justification to the "start digging" argument of the Willie Browns of the world. It perfectly fits the "propensity for action" found with project promoters and developers, a fact Hirschman (1967a: 21) was well aware of. Hirschman was that rare type of scholar who is as interested in practice as in theory, and he successfully sought influence on policy with his ideas, including the Hiding Hand. This makes the Hiding Hand particularly interesting, but also especially problematic, because it is the type of theory that for many policy makers and practitioners, even if wrong, is just too good to give up. And wrong it is, as we will see later, with potentially disastrous consequences when applied in policy and practice.

This is not to question the general giftedness of Hirschman's work or his status as "eminent 20th century intellectual" (Offe 2013: 584) and "one of the great heroes of economics" (Rodwin 1994: 36). ${ }^{3}$ But it is time to rigorously test Hirschman's Hiding Hand principle, which has not been done before. In a private comment made to his close friend and later Nobel laureate, the Harvard economist Thomas Schelling, Hirschman explained, at the time of writing up the principle of the Hiding Hand for publication, that this work was "an exploration, an experiment and I need [as] a critic someone who can understand that in the first place, and then tell me where I may have gone wrong" (Adelman 2013: 404, emphasis in original). ${ }^{4}$ Below, the present author proposes to be this critic, who Hirschman asked for but never had.

\section{What Is the Hiding Hand?}

After having studied the outcomes of a number of World Bank-financed development projects, Hirschman (1967a: 12) noticed, in Development Projects Observed: ${ }^{5}$

"If the project planners ... had known in advance all the difficulties and troubles that were lying in store for the project, they probably would never have touched it ... advance knowledge of these difficulties would therefore have been unfortunate." 
As a case in point, Hirschman (1967a: 9-10) highlights East Pakistan's (now Bangladesh) Karnaphuli paper mill, the biggest in Asia at the time of its construction. The plan was to use vast, easily accessible bamboo forests as the main source for paper pulp. However, soon after the mill opened, as a freak incident of nature, 85 percent of the bamboo that supported production flowered and died. If the planners had known this, Hirschman argued, they probably would have never proposed and funded the mill. Instead, the managers were now forced to creatively find other sources of pulp, which they did from imports, collecting bamboo in other parts of the country, using lumber, and researching fast-growing bamboo species that might replace the unreliable original source, thus creatively diversifying the raw material base. To be sure, this was more costly and difficult than the original plan, but as a result the mill survived and created jobs for thousands of people, argued Hirschman.

Hirschman (1967a: 13, 16) was strongly influenced by Sawyer's (2014/1952) concept "creative error" and was quick to label the workings of creativity in saving wayward projects a "general principle of action" and the Hiding Hand a "fairly general phenomenon." He explained that the reason he saw advance knowledge about costs and difficulties as unfortunate was that such knowledge was likely to result in a "gloomy view" (12) of the ability to meet the budget and overcome challenges, which might stop projects before they got started. Ignorance was better, Hirschman argued, because humans tend to also ignore or underestimate their ability in dealing with difficulties. Ignorance therefore "tricked" (13) people into doing projects they would not otherwise have done:

"[S]ince we necessarily underestimate our creativity, it is desirable that we underestimate to a roughly similar extent the difficulties of the tasks we face so as to be tricked by these two offsetting underestimates into undertaking tasks that we can, but otherwise would not dare, tackle. The principle is important enough to deserve a name: since we are apparently on the trail here of some sort of invisible or hidden hand that beneficially hides difficulties from us, I propose the Hiding Hand ... The Hiding Hand is essentially a way of inducing action through error, the error being an underestimate of the project's costs or difficulties." (Hirschman 1967a: 13, 29 emphasis in original).

In coining the name for his newfound principle, Hirschman played on one of the most famous concepts in economic theory, Adam Smith's Invisible (Hidden) Hand. This indicates just how theoretically ambitious Hirschman was with the Hiding Hand and how significant he took it to be. He was explicit that he saw the 
principle as a theory, at first calling it the "theory of providential ignorance," only later changing this to the "principle of the Hiding Hand" (Alacevich 2014: 157). Hirschman (1967a: 1, 3, 7, 13) also emphasized that although his focus was on development projects he saw the principle-cum-theory as a "general" one that applies across project types and geographies in both developed and developing nations. This is not to say that Hirschman (1967a: 13) thought the Hiding Hand - with its two offsetting underestimates of costs and benefits - would apply to each and every project across all time and space. He was well aware that projects exist, "from bankruptcies and white elephants to lost or ruinously won wars," for which cost underestimates had not been offset by even larger benefit underestimates, but had instead been exacerbated by overestimated benefits followed by benefit shortfalls (Hirschman 1967a: 30). Hirschman therefore duly presented his principle with a number of caveats, calling the Hiding Hand a "very broad" and "speculative" proposition useful only "[u]p to a point," and warning that "by itself trouble does not constitute a sufficient condition for a 'creative response' [by project planners]" (Hirschman 1967a: 7, 11, 12, 14). ${ }^{6}$ Stronger than the caveats, however, and prominently placed on page one of his book, Hirschman maintained that the Hiding Hand was aimed at understanding "project behavior in general" and that the principle "typically" applies, i.e., in more cases than not (Hirschman 1967a: 1, 13). Accordingly, he gave the Hiding Hand what he later called "pride of place" in Development Projects Observed, giving name to and taking up the first chapter of the book (Hirschman 1995a: ix). Sunstein (2015a: 1-2), in his foreword to the 2015 edition, rightly calls the Hiding Hand the "largest idea" in the volume and explains that "the result of the Hiding Hand is to produce an outcome that is as good as what the planner originally thought - or perhaps even better."

The key mechanism driving the Hiding Hand is optimism caused by an ignorance of difficulties, including costs, which leads people to take on tasks they would not have taken up had they known the real challenges involved:

"The principle [of the Hiding Hand] suggests that far from seeking out and taking up challenges, people typically take on and plunge into new tasks because of the erroneously presumed absence of a challenge, because the task looks easier and more manageable than it will turn out to be" (Hirschman 1967a: 13). 
Behavioral economists would later use terms like overconfidence bias, the planning fallacy, and optimism bias to describe and problematize the type of behavior Hirschman observed (Gilovich et al. 2002). Sunstein (2015a: 4) goes so far as to say that Hirschman "can easily be seen as an early behavioral economist" and that Development Projects Observed "can plausibly be counted as a work in behavioral economics." Further on, we will see whether this is a reasonable interpretation and what may be learned from Hirschman and the Hiding Hand in terms of behavioral economics. For now, we conclude that the key to understanding the principle of the Hiding Hand is its emphasis on the "two offsetting" or "double" underestimates of costs/difficulties and benefits/problem-solving abilities, where the latter comes to the rescue of projects that have been tripped up by the former (Hirschman 1967a: 13, 16).

Hirschman does not stop here, however. He further describes the functioning of the Hiding Hand as a learning process where the trickery of the Hand serves as a pair of "crutches" for the decision maker or planner,

"permitting him to go forward at a stage when he has not yet acquired enough confidence in his problem-solving ability to make a more candid appraisal of a project's prospective difficulties and of the risks he is assuming. The experience of meeting with these difficulties and risks and of being able to deal with them should then enable him to discard these crutches and to achieve a more mature appraisal of new projects ... The Hiding Hand is essentially a mechanism that makes the risk-averter take risks and in the process turns him into less of a risk-averter" (Hirschman 1967a: 26).

In this way, through "mechanisms of self-deception," the Hiding Hand tricks decision makers into taking risks they would not otherwise have taken, which is good, according to Hirschman, because this teaches them (a) what the risks are, (b) that the risks are manageable, and (c) that it is therefore okay to be less risk averse for future projects (Hirschman 1967a: 34). "The Hiding Hand is thus essentially a transition mechanism through which decision makers learn to take risks, and the shorter the transition and the faster the learning the better," explains Hirschman (1967a: 28, 34; emphasis in original). Quick learning is desirable because it makes decision makers and planners "able to differentiate between acceptable and nonacceptable risk," thus bringing risks down over time with the help of the Hiding Hand. "You have to do all these fool things before you do the sensible things," Hirschman wrote in his field notes (Bianchi 2011: 18). 
In sum, the Hiding Hand does its work through beneficial ignorance - or "ignorance of ignorance" as Hirschman (1967a: 35) put it. Beneficial ignorance hides two things from decision makers. First, the true costs and difficulties of projects remain obscure, which makes planners take up projects they would not have considered, had they known their true complications. Second, the Hiding Hand also conceals planners' problemsolving ability in dealing with costly and difficult projects, which makes planners able to successfully deal with such projects when the difficulties manifest themselves, at which time the planners' concealed abilities become overt and save the day. Overall, the Hiding Hand is therefore a good thing, according to Hirschman and his followers, because it makes projects go ahead and succeed - based on beneficial ignorance - that would not have done so had planners known at the outset the real costs and difficulties, exactly like Willie Brown argues in the introduction above.

\section{Reception of the Hiding Hand}

Believing he had happened on a big idea and pleased with his allusion to Adam Smith, Hirschman went looking for a large audience. He found it in the readership of The Public Interest, a magazine on political economy and culture, edited by Daniel Bell and Irwing Kristol, aimed at policy makers, fellow scholars, and journalists. Kristol helped Hirschman revise into a more readable article Chapter One of Development Projects Observed, about the Hiding Hand (Hirschman 1967b). The article had immediate influence, while the book at first was a bit of a flop but later gained traction, including with new editions. Hirschman's ideas were picked up by policy makers and practitioners - from Washington's policy establishment to the United Nations, to the World Bank and development agencies around the world (Adelman 2013: 405). Göran Ohlin, a Swedish diplomat and professor of economics, wrote from the United Nations that he was applying the new concept to industrial development. Andy Kamarck, head of the World Bank's Economics Department, told Hirschman:

"You've helped in part to remove the unease that I have had in reflecting on the fact that if our modern project techniques had been used, much of the existing development in the world would never have been undertaken. It may be that with a further working out of the ideas that you explore in this chapter [Chapter One, "The Principle of the Hiding Hand"], we can avoid this future inhibitory role of economists" (Adelman 2013: 405). 
Hirschman's (1967a: 12) explicit endorsement of ignorance as beneficial appealed to promoters and developers of projects. It is easy to understand why. In general, developers like nothing better than to be allowed to proceed with their projects, since this is their job. And the principle of the Hiding Hand is a theory that encourages exactly that. It explains why decision makers should just go ahead and not worry too much about costs or other difficulties. It predicts they will be okay in doing so, because the Hiding Hand, with its emphasis on human problem-solving abilities in challenging situations, will overcome the difficulties. With such reasoning from a leading economist and founding father of development economics, who would want to be the killjoy arguing against large projects by fretting about their challenges? Instead, the principle of the Hiding Hand justifies optimism and a propensity for action, both of which resonate deeply with the mentality of project promoters, developers, and other bullish people. This, more than anything else, explains why the mechanism of the Hiding Hand has had the deep and long-lasting influence it has. It also explains why lock-in and escalation of commitment are so pervasive in major project management, and why project abandonment rates are low (Cantarelli et al. 2014; Drummond 2014). ${ }^{7}$

Picciotto (1994a: 341), vice president and veteran of the World Bank, explained that Development Projects Observed "has long been an inspiration to project officers ... because it validates their day-to-day experience." Picciotto did not hesitate to call the book a "classic," as have many others, and to point out that Hirschman's ideas, which at first seemed subversive to some, including staff at the Bank, have become mainstream (Gasper 1986: 467; Rodwin 1994: 31-32; Alacevich 2014).

The article and the book also made their impact in academia, although more slowly at first. David Riesman, a fellow author from The Public Interest, was an early adopter, when he assigned Hirschman's article to his students at Harvard (Adelman 2013: 405). Later, the article and book became standard fare in university courses around the world in topics like decision making, project management, development economics, economic geography, planning, evaluation, and appraisal. Hirschman's work even received the rare honor of having a whole academic book dedicated to its exploration, with the Hiding Hand featuring prominently, and with contributions by scholars like Nobel laureate Paul Krugman of Stanford, Karen Polenske and Donald Schön of MIT, and Jesse Ribot of Harvard (Rodwin and Schön 1994).

There has also been critique, needless to say. Scholars and practitioners looking for clear, replicable appraisal standards were disappointed, including promoters of ex ante cost-benefit analysis (Alacevich 2014: 
153, 156, 161-64; Little and Mirrlees 1974; Reutlinger 1970; Squire and van der Tak 1975). As observed by Lepenies (2008) and Bianchi (2011), with the Hiding Hand Hirschman pointed a finger at cost-benefit analysis, which enjoyed high prestige among World Bank experts, and his targets responded in kind. Others found Hirschman's arguments "unconvincing" (Lal 1983: 176; Cracknell 1984: 17). Despite the critique, nearly 50 years after its initial publication, Development Projects Observed is still going strong, with a celebration of its ideas, including the Hiding Hand, by Malcolm Gladwell in The New Yorker (Gladwell 2013), a dedicated study by a professional historian of the genesis of the book calling it "groundbreaking" (Alacevich 2014: 139), and a new edition with an enthusiastic preface by Sunstein (2015a) emphasizing the importance of the Hiding Hand. ${ }^{8}$ The book is rightly considered among Hirschman's more influential and the Hiding Hand among his more powerful ideas. Further securing the legacy of this and other work by Hirschman is Adelman's (2013) comprehensive intellectual biography, accompanied by an extensive review in The New York Review of Books calling Hirschman's work an "enduring achievement" (Sunstein 2013: 17).

\section{But Is It a Theory?}

We saw above that Hirschman originally and explicitly used the term "theory" to describe the basic idea behind the principle of the Hiding Hand, namely that ignorance is good when making decisions about projects, because without ignorance projects would not get started (Alacevich 2014: 157). We also saw that Hirschman insisted that the Hiding Hand is a principle of action aimed at understanding "project behavior in general," across project types, organizations, and geographies, including both developed and developing nations (Hirschman 1967a: 1, 13, emphasis added).

Nevertheless, several students of Hirschman argue that the principle of the Hiding Hand is not a theory and that Hirschman was averse to theorizing. Sunstein (2015: 1), for instance, writes that Hirschman "distrusted large claims and law-like generalizations." Adelman (2013: 115-16, 124, 145-46, 198, 236, 420-22, 503, 582, 620, 647) similarly emphasizes Hirschman's attraction to "petites idées" and dislike for "grand theory." Bish Sanyal directly calls Hirschman "antitheoretical" (Rodwin and Schön 1994: 320). In comments to an earlier version of the present paper, Adelman (2015) explains: 
"[Hirschman] was decidedly averse to 'theory,' as you know. And you keep insisting that he calls this a theory of the hiding hand. The key word is principle, much more in accord with the heuristic style of classical political economy. He does not seek a causal claim that travels across all time and place, and thus would fully appreciate that his 'principle' does not apply in many cases" (emphasis in original).

Similarly, Sunstein (2015b) in comments to the author on the same version of the paper:

"You might categorize Hirschman not as a standard economist, testing hypotheses, but instead as something more like a keen observer, a bit like a novelist, who uncovers mechanisms and phenomena that other people hadn't. That's how I take the idea of a hiding hand - not as a hypothesis, but as a mechanism ... [Hirschman is] offering a narrative about a mechanism, not a testable hypothesis."9

Adelman is right that the key word Hirschman settled on - after first using "theory" - is "principle." But Adelman is wrong that the principle is not a theory and that Hirschman was averse to theory. ${ }^{10}$ Hirschman (1994: 277-78) is himself direct and unambiguous on the latter point:

"I am not ... set against paradigms and theorizing. For I like to claim that I have come up with quite a few theoretical notions of my own ... from the ... 'supply effect' ... to ... 'unbalanced growth' ... to ... my 'tunnel effect.' So I bristle a bit when I am pigeonholed as 'atheoretical' or 'antitheoretical"' (Hirschman 1994: 277-78).

In the same tenor, Hirschman talks explicitly about his "theoretical bent" and describes his work as having "the hallmark of useful theory building" just as he is clear and self-reflected regarding his "contribution to development theory" (Hirschman 1994: 278, emphases added). There can be no doubt, therefore, that Hirschman saw himself as doing theory and that he was not against theorizing.

The misunderstanding that Hirschman was averse to theory seems to have arisen from three sources. First, as observed by Offe (2013: 588-589), Hirschman accomplished the paradoxical feat of making a "theory about 
the futility of theorizing," which seems to have thrown people. Hirschman theorized that theories about the world may actually prove an obstacle to understanding and to effective action. In this sense Adelman and others are correct that Hirschman is against theory. But he is against only a certain type of theory - the synoptic kind - not theory in general. And this does not make Hirschman's own work atheoretical, as rightly noted by Offe.

Second, Hirschman's focus on petites idées appears to have led to the view that focusing on the particular would stand in opposition to focusing on the general and on theory, not to speak of grand theory, ref. Adelman earlier. But Hirschman makes clear that for him an opposition between the particular and the general does not exist: "Immersion in the particular proved, as usual, essential for the catching of anything general," he wrote in the Introduction to Development Projects Observed, dissolving the conflict between the two (Hirschman 1967a: 3). Hirschman followed an old and fundamental phenomenological insight, that small questions often lead to big answers, and that as a scholar you therefore need to do work that is at the same time as detailed and as general as possible. Such an approach voids the opposition of small and big, of petites idées and theory. One leads to the other, instead of excluding it, according to this line of thought, which is why Hirschman emphasized both petites idées and theory (Flyvbjerg 2001: 133-34).

Third, there is a confusion in the literature about Hirschman of two different uses of theory, for explanation and for design. The use of theory for explanation is what Hirschman talks about above, and he had no issue with this, not for himself and not for other social scientists, except that some theories explain better than others, needless to say. The use of theory for design, where law-like ideas are used to prescribe and plan social action, or even the social order, is a different matter. Hirschman generally saw such social engineering - whether driven by experts or revolutionaries - as highly problematic and bound to fail. He was against theory used in this manner, especially in development policy. However, in the present paper we focus on theory as explanation, and the principle of the Hiding Hand was very much developed by Hirschman to be such a theory, with truth claims and causal mechanisms.

To illustrate, we saw previously that in formulating the principle of the Hiding Hand, Hirschman (1967a: $13,15)$ made the statement that "people typically take on and plunge into new tasks because of the erroneously presumed absence of a challenge, because the task looks easier and more manageable than it will turn out to be ... [T]otal costs are underestimated and investment decisions activated in consequence." This central statement is a truth claim about how people behave when starting new projects and it explicates both causal mechanisms ("because," "in consequence") and theses that may be tested. With the word "typically," Hirschman clearly 
indicates that the depicted behavior applies more often than not, which is a specific thesis that may be tested empirically, as done below. The same applies to the statement that "costs are underestimated," also tested below. There is nothing in this truth claim that is alien to theorizing, explanation, and hypothesis testing, and in this sense the principle of the Hiding Hand is a theory: It explains, it predicts, it is testable. Adelman, Sunstein, and others are therefore wrong when they deny Hirschman his explicit claims at theorizing.

Adelman and Sunstein are also wrong when they want to reduce the principle of the Hiding Hand to a "heuristic" or "mechanism," respectively. A heuristic is a rule of thumb or an educated guess that works under certain limited circumstances, but without claims of general applicability. This is much too modest an interpretation of the principle of the Hiding Hand. We saw earlier that Hirschman repeatedly emphasized that the principle is a general one, and that it applies across project types and geographies. Adelman is right, however, that Hirschman does not seek a causal claim that travels across "all" time and place. But few, if any, social science theories apply to all time and place, so this is hardly a useful criterion to identify the Hiding Hand as less of a theory than other work in the social sciences. Hirschman (1967a: 13, 16-17) explicitly says the Hiding Hand "typically" applies - that is, more often than not - and he explains how it applies (by a "double underestimate" of costs/difficulties and benefits/problem-solving abilities). This is enough to qualify as theory, and it is much more than a heuristic.

Sunstein is right when he says that Hirschman is not a standard economist. But Sunstein is wrong when he describes Hirschman as mainly a "novelist" who uncovers what others overlooked. Hirschman, too, would not agree with this. Hirschman (1994: 278) rejects Sunstein on this point in the following manner:

"I ... cannot wholly agree when I am portrayed ... as someone who is primarily interested in noticing and underlining what more systematic-minded (theoretical) economists or social scientists have overlooked" (parenthesis in original).

Sunstein is here also at odds with his own description above of Hirschman as an early behavioral economist and of Development Projects Observed as a work in behavioral economics (Sunstein 2015a: 4). Behavioral economics is all about theorizing and hypotheses testing. So to claim Hirschman for this particular brand of economics and at the same time call him a novelist not interested in hypotheses testing seems self-contradictory. 
Finally, Sunstein and Adelman are wrong when they say the principle of the Hiding Hand is not testable. They might be right that such test was not a main concern for Hirschman. But that does not mean the truth claims of the Hiding Hand could not or should not be tested. And perhaps Hirschman should have paid more attention to this, as we will see below. In what follows we test the Hiding Hand for, first, validity of methodology, and, second, robustness of results.

\section{Validity of the Hiding Hand}

It turns out that Hirschman's ideas about the Hiding Hand are based on an exceedingly small number of observations and biased data. Hirschman studied only 11 development projects financed by the World Bank, spread over four continents (Hirschman 1967a: 2-3). ${ }^{11}$ To be fair, large amounts of empirical data were not available at Hirschman's time, so it might have been impossible to collect data for a large sample, even if he had wanted to do this. Nevertheless, 11 projects is much too limited a dataset to support the wide conclusions drawn, as we will see. Moreover, Hirschman's small sample size has typically been ignored or papered over in the secondary literature on the Hiding Hand, leaving the impression that the empirical foundations of the principle are solid. This has become conventional wisdom, because, as often happens, the secondary literature has attracted more readers than the primary source. Elster (1983: 158), for instance, says that Hirschman did "numerous case studies" in support of the Hiding Hand; Catino (2013: 62) that Hirschman based the principle on "many projects analyzed." Other authors have glossed over the problem of sample size by euphemistically talking of "a number of" (Cracknell 1984: 17), "a series of" (Alacevich 2014: 139), or "various" (Lepenies 2008: 450) projects studied by Hirschman, or they simply reported his results without reference to the sample size at all, like Klitgaard (1997: 1963). It is interesting to note that once a theory has become generally accepted and widely popular, apparently even highly regarded scholars do not bother to check and report on its empirical basis, not to speak of testing it. Based on such writings, which are typical of the literature on the Hiding Hand, readers have been led to believe that the empirical foundation of the Hiding Hand is sound. Only by going back and checking the primary source would a reader get an inkling that, in fact, a big question mark hovers over the principle of the Hiding Hand in terms of the most basic issue for any scholarly work, that of validity and reliability. World Bank officials encouraged Hirschman to enlarge his sample size. But Hirschman wanted to be able to personally visit each project and do his own interviews and observations on site, which made a large 
sample impractical. So he stuck to his 11 projects, despite initial critique, which was silenced by the popular appeal and positive reception of the work.

In addition to issues of sampling, a second problem with Hirschman's study of the Hiding Hand is biased data collection. Adelman (2013: 388) has systematically gone through the "abundance of field notes" behind the study. He found the notes convey "a strong impression of basic confusion." Hirschman apparently "struggled to make sense of his observations" and "was having difficulty keeping his endeavor clear," because so many of the projects seemed idiosyncratic, whereas Hirschman wanted to ignore peculiarities in favor of "some broad brush strokes" (Adelman 2013: 388, 396). One might speculate that Hirschman's need for order and broad strokes became particularly strong exactly because of the confused state of his data collection. In any case, the principle of the Hiding Hand eventually became the main stroke.

According to Hirschman's notes, the "running theme" for the many project managers he interviewed was "that their projects had 'failed"' (Adelman 2013: 389). However, Hirschman "tended to be more hopeful than his witnesses," judging by his notes and his book, and he insisted on looking for things that worked despite the frustration of his informants. "Identifying silver linings was becoming an occupational habit" for Hirschman, according to Adelman (2013: 392) - and, one might add, an occupational hazard, because Hirschman's disordered approach meant that his biases ("silver linings") were never systematically problematized and tested for validity. Instead, Hirschman's optimism survived unproblematized through data collection; it "blinded him," and "his wish for surprising, positive effects overwhelmed what he saw and heard," according to Adelman's (2013: 393) detailed analysis of the archives. ${ }^{12}$ Picciotto (1994b: 303) similarly observes that for Hirschman the reality of the development process, including principal-agent problems and other systemic difficulties, was "all cloaked in optimism and romanticism." In the present author's view, it might be completely legitimate - perhaps even ingenious - for a scholar to look for success where others see failure. But this would require the scholar to be open about his or her approach, so others may test it. This is not what Hirschman did. For whatever reason, intentionally or not, Hirschman concealed his biased data collection, which made it appear that the Hiding Hand was an attribute of the projects he studied, when it was, in fact, more an attribute of his biases and "the story he spun" to fit his data, which eventually became the story of the Hiding Hand (Adelman 2013: 394). The optimism of the Hiding Hand is that of its author and is not justified by the evidence - not even Hirschman's own evidence, as revealed in his field notes - according to this analysis. Offe (2013: 588) observes that Hirschman's optimistic model of development - where unforeseen challenges provide opportunities for creative solutions followed by 
success - is a "mirror image of his own life experience," from his escape from Nazi Germany to life as an immigrant in France, England, Italy, Spain, and the US. Offe speculates that this personal experience is the root cause of the pervasive optimism in Hirschman's scholarly work. ${ }^{13}$ In Hirschman's (1971) own words, he had a "bias for hope" to a degree where this became the title of one of his later books.

Yale political scientist Charles Lindblom, who had earlier accompanied Hirschman on field research, warned him of the dangers of his approach (Adelman 2013: 396). So did Walter Salant of the Brookings Institution, who pointed out in a private note to Hirschman that his analysis was one-sided in the sense that it tackled only cases "where the difficulties and abilities to solve them were underestimated" (Adelman 2013: 404). Hirschman agreed in private that this was an issue and he admitted he had wanted "to emphasize unexpected successes" in his sampling and data collection, in order to show how the Hiding Hand might get risk averters to act (Adelman 2013: 405). Nowhere in Hirschman (1967a, b) is the biased data collection mentioned, however, leaving the impression that Hirschman's Hiding Hand is an ex-post empirical finding obtained from studying his data, when in reality it is a methodological artifact of how the data were collected, including only observations that would affirm the Hiding Hand. Not until 30 years later did Hirschman (1995a: viii) reveal that he had a "hidden agenda" when collecting data for the Hiding Hand, namely "to celebrate, to 'sing' the epic adventure of development - its challenge, drama, and grandeur."

In his foreword to the 2015-edition of Development Projects Observed, Sunstein (2015a: 5) suggests that an "uncharitable reading" of the book would indicate that Hirschman has committed the fallacy statisticians call "sampling on the dependent variable." Sunstein understandably has to be charitable to Hirschman in a foreword to his classic text. One could argue, however, that pointing to Hirschman's fallacy is not an uncharitable reading but a precise and balanced one, and that this fallacy renders Hirschman's study invalid in scholarly terms. However, Sunstein's (2015a: 4) interpretation of Hirschman as an early behavioral economist, and of his publications on the Hiding Hand as works in behavioral economics, are a stretch. Hirschman's methodology is too non-rigorous and his data too low-quality, compared with mainstream behavioral economics. Moreover, contrary to behavioral economists, who tend to see overconfidence and bias as negative to outcomes, Hirschman emphasizes the positive aspects of biased behavior, because overconfidence and optimism are what trigger the Hiding Hand. Instead of seeing Hirschman as an example of an early behavioral economist we might better see him as a case for behavioral economists to study: a case of how damaging optimism bias can be, not only in policy and business, but in scholarship as well. Hirschman was a victim, not a student, of bias. 
The present author shares Hirschman's view that the ability to problem-solve when unforeseen challenges arise is more important to success in large-scale ventures than even the best-laid strategies, synoptic planning, and cost-benefit analyses. But with the Hiding Hand Hirschman optimistically assumes that problem-solving abilities will be triggered when needed, instead of making this a question for empirical test. This is Hirschman's main error: he mistook, and misrepresented, his own optimistic view for empirical reality. All would have been well if Hirschman had claimed no more and no less than (i) to have developed certain ideas, most importantly the Hiding Hand, based on studying a small sample of projects, (ii) that these ideas, in his view, might be useful for understanding and planning large projects, and (iii) to warn that due to the small sample size, and because he deliberately collected data to emphasize success, it is impossible to know how often and where the ideas apply in the wider population of projects; further study would have to clarify this. That would have been an honest and balanced way for Hirschman to present his study. Instead, he overextended his ideas, and especially the Hiding Hand, as a general principle of action. The fact is that neither Hirschman nor we know whether the Hiding Hand is in reality such a general principle, or just how general or local it is. Fifty years after the formulation of the principle, no one has tested this in scholarly terms. Such test is the subject of the following section.

\section{Statistical Test of the Hiding Hand}

We saw previously that Hirschman developed the principle of the Hiding Hand based on data from 11 large projects. Below, we will test the principle against a bigger and better dataset, consisting of 2,062 such projects. We will see whether Hirschman's results are replicated with the greater sample. Such a test has not been done previously. ${ }^{14}$ The data are from the largest database of its kind. The data cover the eight project types listed in Table 1. We see they are infrastructure projects like most of the projects in Hirschman's smaller sample. ${ }^{15}$ For each project in the dataset, two data points were measured, namely cost overrun and benefit overrun, respectively. Geographically, the dataset includes projects in 104 countries on 6 continents, covering both developed and developing nations. Historically, the data cover almost a century, from 1927 to 2013. Older projects were included to enable analyses of historical trends. Data of this kind are difficult to come by. No statistical agency or other data service exist, from which such data may be obtained. The data therefore have to be mined data point by data point from the source, which is extremely time consuming, and which is why it took the author and his colleagues 20 years to arrive at the dataset presented here. Data collection systematically 
followed international standards. Projects were included on the basis of data availability. ${ }^{16}$ All projects that the author knew of for which data on cost overrun and/or benefit shortfall were obtainable were considered for inclusion in the sample. Data were collected from a variety of sources, including annual project accounts, cost and procurement accounts, revenue accounts, auditors' data, questionnaires, interviews, and other studies. Some data had to be rejected due to insufficient data quality, approximately 25 percent of cost data and 50 percent of benefit data. In sum, all projects for which data were considered valid and reliable were included in the sample. Data collection and the database are described in more detail in Flyvbjerg et al. (2002, 2005a) and Flyvbjerg (2005b).

Developing testable theses from Hirschman's work must involve a degree of cautiousness and careful argument as must the use of statistical methods to test his ideas. ${ }^{17}$ We saw earlier that the key mechanism of the Hiding Hand is that people get tricked by their ignorance of costs and difficulties into starting projects, but once the projects are ongoing, people find similarly underestimated problem-solving abilities to overcome and more than compensate for the initial costs and difficulties, making their projects succeed. Based on the projects he observed, Hirschman (1967a: 12-13) specifically describes the key mechanism like this:

"the difficulties [initially encountered by a project] and the ensuing search for solutions set in motion a train of events that not only rescued the project but often made it particularly valuable."

In this manner, projects end up as viable, i.e., with net benefits. Hirschman's main truth claim regarding the Hiding Hand may therefore be stated like this:

Claim no. 1: Higher-than-estimated project costs/difficulties are typically outweighed by even higher-than-estimated project benefits/problem-solving abilities.

Table 1 shows the results from a test of the claim that higher-than-estimated project costs/difficulties (cost overrun) will be outweighed by even higher-than-estimated benefits/problem-solving abilities (benefit overrun). Ideally, costs, benefits, etc. would be measured over the full life-cycle of a project. However, such data are rarely, if ever, available. International convention is therefore to measure costs/difficulties by the proxy of construction costs and benefits/problem-solving abilities by the proxy of first-year benefits. This convention is 
followed here. ${ }^{18}$ Cost overrun is measured as actual divided by estimated cost in real terms; benefit overrun is measured as actual divided by estimated usage, e.g., traffic for transportation infrastructure and power generation for energy infrastructure. For both costs and benefits, overrun is calculated with the baseline in the final business case, i.e., the date of the decision to build. Taking rail as an example, average cost overrun is listed in Table 1 as 1.40, which means that for rail projects actual costs turned out to be 40 percent higher than estimated costs on average and in real terms. Average benefit overrun for rail is listed as 0.66 , which is evidence of a benefit shortfall of 34 percent, meaning that on average 34 percent of the estimated passengers never showed up on the actual trains. If the basic idea of the Hiding Hand were correct, average benefit overrun would be larger than average cost overrun. We see this is not the case for rail projects or for any of the eight project types in Table 1 . From the p-values in Table 1 we see that the rejection of the Hiding Hand applies at an overwhelmingly high level of statistical significance $(\mathrm{p}<0.0001$, Mann-Whitney test), a level that is rarely found in studies of social phenomena. ${ }^{19}$ We ran the same tests with similar results for a subsample of 327 projects for which data were available for both cost overrun and benefit overrun for each project. ${ }^{20} 21$

[Table 1 app. here]

It is particularly noteworthy for these tests, that on average not only is benefit overrun not larger than cost overrun, as the Hiding Hand says it would be, but there is no benefit overrun at all. Instead we find the opposite, namely a benefit shortfall (benefit overrun $<1$ ). This shows that Hirschman's idea of the Hiding Hand is wrong both by degree and by direction as it gets the size as well as the sign (minus instead of plus) wrong for benefit overrun. Instead of projects that generate benefits that compensate for cost overruns, as optimistically theorized with Hirschman's (1967a: 13) "two offsetting underestimates," in reality the average project is impaired by a twofold blow of substantial cost overruns compounded by substantial benefit shortfalls. This is bad for viability, needless to say, and if projects are large enough and the economies where they are built are fragile, just one major project gone wrong can negatively affect the national economy for decades, as Brazil and Pakistan have learned with their large-dams projects (Ansar et al. 2014), and Greece with the 2004 Olympics (Flyvbjerg and Stewart 2012). This problem is not limited to public sector projects. Cost overruns, delays, and revenue shortfalls on the Airbus A380 jumbo jet put the company at risk and cost top management their jobs; K-Mart went out of 
business due to a billion-dollar IT project similarly gone wrong (Flyvbjerg and Budzier 2011). Where is the Hiding Hand when you need it, the owners of these projects might rightly have asked.

Sunstein (2015a: 4) adds an interesting and useful twist to the Hiding Hand, when he claims that the Hand has an "evil twin." Picciotto (1994b: 302) similarly observes that "[t]here might be two hiding hands." One is a Benevolent Hiding Hand, which is Hirschman's topic, the other a Malevolent Hiding Hand, "which also hides obstacles and difficulties, but in situations in which creativity does not emerge, or emerges too late, or cannot possibly save the day" (Sunstein 2015a: 4-5). ${ }^{22}$ For such situations, Streeten (1984: 116) talked about the "Principle of the Hiding Fist." Hirschman did not deny that circumstances like this may exist, but he never tested the obvious question as to which of the two Hiding Hands was the more common empirically, the benevolent or the malevolent one, and neither did Sunstein, Picciotto, Streeten, or anyone else. This question was not Hirschman's interest and instead he optimistically claimed, based on the biased evidence from his small set of World Bank projects, that the Benevolent Hiding Hand is typical and thus more common than the Malevolent Hiding Hand. However, based on the data presented previously we must reject this claim. According to the data, the "evil twin" - the Malevolent Hiding Hand, for which higher-than-estimated costs are not outweighed by even higher-than-estimated benefits - vastly outnumbers the Benevolent Hiding Hand, namely by a factor four to one. And again the rejection applies at an overwhelmingly high level of statistical significance, indicating just how wrong the claim of the Benevolent Hiding Hand is ( $\mathrm{p}<0.0001$, Mann-Whitney test, one-sided). Instead of Hirschman's Benevolent Hiding Hand being typical, as Hirschman theorized, the Malevolent Hiding Hand dominates by being present in 80 percent of projects. One might speculate that conceivably the one fifth of the projects that complied with the hiding hand hypothesis (the Benevolent Hiding Hand) may have generated more benefits in the aggregate than the four fifths that did not (the Malevolent Hiding Hand). A test shows, however, at an overwhelmingly high level of statistical significance, that (i) not only is this not the case, but (ii) the opposite happens since the net effect of the Malevolent Hiding Hand is larger than the net effect of the Benevolent Hiding Hand ( $\mathrm{p}=0.001$, two-sided Mann-Whitney test) ${ }^{23}$

It should be stressed that the clear statistical rejection of the Hiding Hand above does not mean that projects do not exist for which the Hiding Hand applies or that such projects may not be an interesting special case for study, as demonstrated by Sawyer (2014). ${ }^{24}$ Even in the dataset used to reject the Hiding Hand it would be easy to select projects that confirm its basic idea. For instance, the German Karlsruhe-Bretten light-rail line, which is in the dataset, had a cost overrun in real terms of 78 percent but an even larger benefit overrun of 158 percent, 
making the project viable, in accordance with the Hiding Hand. Similarly, the Danish Great Belt toll bridge - the longest suspension bridge in the world at the time of completion - had a cost overrun of 45 percent combined with a benefit overrun of 90 percent, again making the project viable and fit the theory. And so on. But to selectively choose data like this and then call what you find a general principle of action, like Hirschman (1967a: 13) does, is methodologically unsound. ${ }^{25}$ Selective data collection is one of the oldest - and most problematic pitfalls in the book of applied statistics. And while Hirschman did not directly select data out of an existing dataset, which would have been data fishing, we know from his notes and private correspondence that during data collection he deliberately emphasized success cases instead of representative ones, to the same effect and without telling his readers. The selective use of data was done discreetly and was glossed over in Hirschman's writings, where it stayed concealed for almost 50 years. Krugman (1994: 287) criticizes Hirschman for seducing - and misleading - people by the "richness of plain English." To be generous to Hirschman, we may speculate that like any true optimist - and Hirschman was clearly an optimist, as argued earlier - he seduced not only his readers but also himself.

\section{Does the Hiding Hand Result in Learning?}

We saw earlier that Hirschman sees the Hiding Hand "essentially" as a "mechanism through which decision makers learn to take risks" and that, therefore, "the faster the learning the better" (Hirschman 1967a: 28; emphasis in original). Specifically, learning via the Hiding Hand makes decision makers better able to reduce risks over time as they find out how to distinguish between acceptable and nonacceptable risks, according to Hirschman, whose second truth claim therefore is:

\section{Claim no. 2: Project risks will tend to fall over time}

Risks will come down over time because of learning from one project to the next, according to this argument. Schön (1994: 69), who studied Hirschman's theory of learning, rightly observes that, "A theory about learning must deal with performance that improves over time. Performance that deteriorates, regresses, or merely swings from one mode of action to another does not qualify as learning." In the context of the Hiding Hand, improved performance would mean a reduction in cost risks and benefit risks over time, if not in the short term 
then in the medium and long run. If the data show such reduction, they support the Hiding Hand on this point. If the data show no reduction, one would have to conclude that no learning takes place and that the Hiding Hand must be rejected here, too.

Figure 1 shows the historical trend in cost and benefit risks, measured as cost and benefit overrun for the projects in Table 1 for which data also exist for opening year. The data cover projects opened to service in the period from 1927 to 2011. If Hirschman's theory of learning were right, then cost overrun would come down over time and benefit overrun would go up, both indicating reduced risks and better project performance. Eyeballing Figure 1, no clear historical trends seem apparent. For cost overrun, Bayesian tests corroborate this impression as no significant relationship is found between cost overrun and time when using all 1271 projects with information for cost overrun and opening year available $(\mathrm{BF}=1.70$, Bayesian test $)$. When we analyze the 327 projects with available information for cost overrun, benefit overrun, and opening year, there appears to be a significant reduction in cost overrun over time $(\mathrm{BF}=134)$ of about 0.5 percent per year. ${ }^{26}$ The latter dataset includes data from 1952 to 2011.

[Figure 1 app. here]

For benefit overrun, the tests show a statistically highly significant historical trend of declining performance of 0.5 percent per year, which again is the opposite of what the theory predicts $(\mathrm{BF}=799)$. This is when using the 625 projects with information about benefit overrun and opening year. When using the 327 projects, the significance disappears and we witness no movement over time, which again runs counter to the theory. Moreover, the intercept is significantly less than one at $0.86(\mathrm{BF}=17)$, indicating that instead of benefit overruns we actually find consistent benefit shortfalls over time, opposite the theory.

For benefit overrun minus cost overrun, there is no significant movement over time, but the intercept stays highly significantly negative $(\mathrm{BF}=2352)$, indicating that benefit overrun is consistently less than cost overrun, once more counter to the theory. This is for the sample of 327 projects. For the period after 1980, the intercept is highly significantly negative at $-1.031(\mathrm{BF}>10000)$ but there is a significant movement over time: benefit overrun minus cost overrun is getting larger by 0.014 per year $(\mathrm{BF}=90)$. This is not a percentage increase, but a nominal yearly increase. However the increase is so small that, starting at the negative intercept, it would take 74 years for benefit overrun minus cost overrun to finally become positive, i.e., before Hirschman's principle would 
become true that higher-than-estimated costs are outweighed by even higher-than-estimated benefits. Finally, the positive trend is not supported by the larger and thus more informative samples of 1271 projects (cost overrun) and 625 projects (benefit overrun), respectively. ${ }^{27}$

In sum, the statistical tests of the Hiding Hand carried out above falsify Hirschman's ideas at an overwhelmingly high level of statistical significance. This conclusion is robust across both conventional and Bayesian testing, and across different samples. Moreover, not only do the data not support Hirschman's main claim - that higher-than-estimated project costs will typically be outweighed by even higher-than-estimated benefits - the data show the exact opposite to be true: The typical (average) project is impeded by a twofold setback of higher-than-estimated costs and lower-than-estimated benefits. This undermines project viability in a majority of cases instead of saving projects by the creative benefit-generation predicted by the Hiding Hand. In other words, Hirschman's Benevolent Hiding Hand is dominated by its "evil twin," Sunstein's Malevolent Hiding Hand. And not only do the data show this dominance to be remarkably consistent across all project types and geographies studied, it is also consistent over time, mainly due to deteriorating project performance on the benefit side, again in diametrical opposition to Hirschman's predictions.

\section{Conclusions}

The present study rejects Albert O. Hirschman's Hiding Hand principle on the following four grounds:

1. Biased data collection. Hirschman chose to focus on unexpected successes in his data collection, without telling his readers, who are therefore left with the impression that the Hiding Hand is an ex-post empirical finding from balanced data collection, when in reality it is a methodological artifact of how the data were collected, including only observations that would affirm the Hiding Hand. Hirschman here got disturbingly close to data fishing and he committed the fallacy that statisticians call "sampling on the dependent variable."

2. Too-small sample. With a sample of just 11 World Bank projects spread over four continents, Hirschman's dataset is much too limited to support the wide conclusions he drew. Unfortunately, the secondary literature on the Hiding Hand has ignored this fact, giving the false impression that the empirical basis of the Hiding Hand is sound. 
3. Misrepresentation of findings. In private, Hirschman called his study "an exploration, an experiment" (Adelman 2013: 404). But to his readers Hirschman (1967a: 13) claimed he had uncovered an economic law - a "general principle of action" - in the tradition of Adam Smith and other great economists. For 30 years Hirschman (1995a: viii) also kept mum about a hidden agenda he had for his study, namely "to celebrate, to 'sing' the epic adventure of development - its challenge, drama, and grandeur." By not telling readers about the explorative and experimental nature of the study, by hiding his biased data collection and the hidden agenda that drove it, by ignoring issues arising from the smallness of his sample, and by claiming much more than his weak and biased data could support, Hirschman misrepresented his findings and misled his readers.

4. False results. A test of whether Hirschman's results may be replicated with a larger and better dataset show this is not the case. Using a sample almost 200 times larger than Hirschman's original one, for which data were collected systematically following international standards, the following was found. First, the main claim of the Hiding Hand theory - that higher-than-estimated project costs will be outweighed by even higher-than-estimated benefits - is rejected at an overwhelmingly high level of statistical significance $(\mathrm{p}<0.0001)$. Not only is benefit overrun not larger than cost overrun, as the theory predicts, on average there is no benefit overrun at all, but the opposite, a benefit shortfall. The Hiding Hand gets both the size and sign (minus instead of plus) wrong for benefit overrun. In reality, instead of the two offsetting underestimates of costs and benefits theorized by Hirschman (1967a: 13), the average project is undermined by a twofold blow of substantial cost overruns compounded by substantial benefit shortfalls. Second, the other main claim of the Hiding Hand theory - that project risks will tend to fall over time (due to learning) - is also rejected. For benefit risks we find a statistically highly significant historical trend of increasing benefit shortfalls of 0.5 percent per year $(\mathrm{BF}=799)$. Again this is the opposite of what Hirschman predicts. For cost risk, no significant relationship is found between such risk and time, i.e., cost risk appears to be more or less constant over time $(\mathrm{BF}=1.70)$. Finally, testing Hirschman's assumption that his Benevolent Hiding Hand (benefit overrun > cost overrun) would be more common than what Sunstein (2015a: 4) calls the "evil twin," the Malevolent Hiding Hand (benefit overrun < cost overrun), we find the opposite to be true: The Malevolent Hiding Hand dominates 80 percent of projects, and again at an overwhelmingly high level of statistical significance $(\mathrm{p}<0.0001)$. 
To be fair to Hirschman, his biases and misrepresentations in developing the Hiding Hand seem to have been driven by a general optimism (his self-declared "bias for hope") and not by deliberate deception, although there is a grey area between the two, which Hirschman entered from time to time. Nevertheless, each of the four points above is enough to leave Hirschman's Hiding Hand significantly invalidated. Taken together, they form a devastating verdict: Nothing about the Hiding Hand is right for understanding "project behavior in general," as was Hirschman's (1967a: 1) declared purpose. The principle applies only to the special cases of success for which it was thought up, and some of those were imaginary, we now know, formed by Hirschman's optimism and hidden agenda more than by evidence on the ground. ${ }^{28}$ This is not to say that the study of success is unimportant, or that Hirschman's work may not be valuable in that context. But if there is a general principle of action at work in the type of behavior Hirschman studied it is the opposite of that postulated by the Hiding Hand: In reality, instead of the success Hirschman (1967a: 16) promises through "creative error," project viability is undercut by a double whammy of substantial cost overruns compounded by substantial benefit shortfalls, as shown in Table 1. Finally, given the results of the present study, it might be a good idea to similarly test some of Hirschman's other work in order to decide which parts stand up to closer scrutiny and which do not.

The Hiding Hand resonates with romantics and cynics alike, which may well explain its lasting influence. Romantics are gratified by its intuitive appeal and its depiction of humans as creative problem solvers who typically land their projects on their feet, despite initial difficulties. Hirschman was clearly a romantic. Cynics see the theory as a means to justifying an end: getting projects started. Willie Brown belongs to this category. Hirschman cannot be blamed for others misusing his principle, needless to say. But he may be criticized for overstating his case. Because of Hirschman's overstatement, using the Hiding Hand unreflectively in policy and practice, as is commonly done, is likely to lead, at best, to the misallocation of scarce resources (Pareto inefficiency) and, at worst, to outright disasters, ranging from white elephants over destroyed careers and companies to national crises and even war, as we saw above. Better theories than the Hiding Hand exist theories of optimism bias, the planning fallacy, and strategic misrepresentation - and these theories should be used in preference to the Hiding Hand for explaining the data and for designing policy and practice (Flyvbjerg et al. 2009). Instead of seeing Hirschman as an example of an early behavioral economist, as Sunstein does, we need to see him as a case for behavioral economists to study: a case of how damaging optimism bias can be, not only in policy and business, but in scholarship as well. Hirschman was a victim, not a student, of bias. However, in rejecting Hirschman we must also - and more importantly - reject the Willie Browns of the world, with their 
self-interested tributes to beneficial ignorance and "start digging." Scholarship should test, not celebrate, such ideas.

\section{References}

Adelman, Jeremy, 2013, Worldly Philosopher: The Odyssey of Albert O. Hirschman, (Princeton and Oxford: Princeton University Press).

Adelman, Jeremy, 2015, personal communication, March 12 and 13, author's archives.

Alacevich, Michele 2007, "Early Development Economics Debates Revisited," Policy Research Working Paper no. 4441 (Washington, DC: The World Bank).

Alacevich, Michele, 2014, "Visualizing Uncertainties, or How Albert Hirschman and the World Bank Disagreed on Project Appraisal and What This Says about the End of 'High Development Theory'," Journal of the History of Economic Thought, vol. 36, pp. 137-168.

Ansar, Atif, Bent Flyvbjerg, Alexander Budzier, and Daniel Lunn, 2014, "Should We Build More Large Dams? The Actual Costs of Hydropower Megaproject Development," Energy Policy, March, pp. 43-56.

Bianchi, Ana Maria, 2011, "Albert Hirschman and His Controversial Research Report," SSRN, papers.ssrn.com/sol3/papers.cfm?abstract_id=1945822, October, 21 pp.

Brown, Willie, 2013, "When Warriors Travel to China, Ed Lee Will Follow," Column, San Francisco Chronicle, 27 July.

Cantarelli, Chantal C., Bent Flyvbjerg, Bert van Wee, and Eric J E Molin, 2014, "Lock-in and Its Influence on the Project Performance of Large-Scale Transportation Infrastructure Projects: Investigating the Way in Which Lock-In Can Emerge and Affect Cost Overruns," originally published in Environment and Planning B: Planning and Design, volume 37, 2010, pp. 792-807, here from Bent Flyvbjerg, ed., Megaproject Planning and Management: Essential Readings, vol. I (Cheltenham, UK and Northampton, MA: Edward Elgar), pp. 424-439.

Cantarelli, Chantal C., Erik J.E. Molin, Bert van Wee, and Bent Flyvbjerg, 2012, "Different Cost Performance: Different Determinants? The Case of Cost Overruns in Dutch Transport Infrastructure Projects," Transport Policy, vol. 22, pp. 88-95.

Catino, Maurizio, 2013, Organizational Myopia: Problems of Rationality and Foresight in Organizations (Cambridge: Cambridge University Press). 
Cracknell, B., 1984, "Learning Lessons from Experience: The Role of Evaluation in the Administration of the U.K. Aid Programme," Public Administration and Development, vol. 4, pp. 15-20.

Drummond, Helga, 2014, "Is Escalation Always Irrational?", originally published in Organization Studies, vol. 19, no. 6, 1998, here from Bent Flyvbjerg, ed., Megaproject Planning and Management: Essential Readings, vol. II (Cheltenham, UK and Northampton, MA: Edward Elgar), pp. 291-309.

Elster, Jon, 1983, Sour Grapes: Studies in the Subversion of Rationality (Cambridge: Cambridge University Press).

Flyvbjerg, Bent, 2001, Making Social Science Matter: Why Social Inquiry Fails and How It Can Succeed Again (Cambridge: Cambridge University Press).

Flyvbjerg, Bent, 2005b, "Measuring Inaccuracy in Travel Demand Forecasting: Methodological Considerations Regarding Ramp Up and Sampling," Transportation Research A, vol. 39, no. 6, July, pp. 522-530.

Flyvbjerg, Bent, 2009, "Survival of the Unfittest: Why the Worst Infrastructure Gets Built, And What We Can Do about It," Oxford Review of Economic Policy, vol. 25, no. 3, pp. 344-367.

Flyvbjerg, Bent, 2011, "Case Study," in Norman K. Denzin and Yvonna S. Lincoln, eds., The Sage Handbook of Qualitative Research, fourth edition (Thousand Oaks, CA: Sage), pp. 301-316.

Flyvbjerg, Bent, 2013, "Quality Control and Due Diligence in Project Management: Getting Decisions Right by Taking the Outside View," International Journal of Project Management, vol. 31, no. 5, May, pp. 760774.

Flyvbjerg, Bent, 2014a, "What You Should Know about Megaprojects and Why: An Overview," Project Management Journal, vol. 45, no. 2, April-May, pp. 6-19.

Flyvbjerg, Bent, 2014b, ed., Megaproject Planning and Management: Essential Readings, vols. I-II (Cheltenham, UK and Northampton, MA: Edward Elgar).

Flyvbjerg, Bent and Alexander Budzier, 2011, "Why Your IT Project May Be Riskier than You Think," Harvard Business Review, September 2011, pp. 601-603;

Flyvbjerg, Bent, Massimo Garbuio, and Dan Lovallo, 2009, "Delusion and Deception in Large Infrastructure Projects: Two Models for Explaining and Preventing Executive Disaster," California Management Review, vol. 51, no. 2, Winter, pp. 170-193. 
Flyvbjerg, Bent, Mette K. Skamris Holm, and Søren L. Buhl, 2002, "Underestimating Costs in Public Works Projects: Error or Lie?" Journal of the American Planning Association, vol. 68, no. 3, Summer, pp. 279295.

Flyvbjerg, Bent, Mette K. Skamris Holm, and Søren L. Buhl, 2005a, "How (In)accurate Are Demand Forecasts in Public Works Projects? The Case of Transportation." Journal of the American Planning Association, vol. 71, no. 2, Spring, pp. 131-146.

Flyvbjerg, Bent, Mette Skamris Holm, and Søren L. Buhl, 2005b, "Credibility Problem for Transit: Response to Millar," Journal of the American Planning Association, vol. 71, no. 4, Autumn 2005, p. 452.

Flyvbjerg, Bent and Allison Stewart, 2012, "Olympic Proportions: Cost and Cost Overrun at the Olympics 19602012," Working Paper, Saïd Business School, University of Oxford, June.

Flyvbjerg, Bent and Cass R. Sunstein, in progress, "The Principle of the Malevolent Hiding Hand; or, the Planning Fallacy Writ Large."

Gasper, Des, 1986, "Programme Appraisal and Evaluation: the Hiding Hand and Other Stories," Public Administration and Development, vol. 6, pp. 467-474.

Gilovich, Thomas, Dale Griffin, and Daniel Kahneman, 2002, eds., Heuristics and Biases: The Psychology of Intuitive Judgment (Cambridge: Cambridge University Press).

Gladwell, Malcolm, 2013, "The Gift of Doubt: Albert O. Hirschman and the Power of Failure," The New Yorker, June 24 .

Hirschman, Albert O., 1958, The Strategy of Economic Development (New Haven: Yale University Press).

Hirschman, Albert O., 1963, Journeys Toward Progress: Studies of Economic Policy-Making in Latin America (New York: Twentieth Century Fund).

Hirschman, Albert O., 1967a, Development Projects Observed (Washington, DC: Brookings Institution).

Hirschman, Albert O., 1967b, "The Principle of the Hiding Hand," The Public Interest, Winter, pp. 10-23.

Hirschman, Albert O., 1971, A Bias for Hope: Essays on Development and Latin America (New Haven, CT: Yale University Press).

Hirschman, Albert O., 1994, "A Propensity to Self-Subversion," in Lloyd Rodwin and Donald A. Schön, eds., Rethinking the Development Experience: Essays Provoked by the Work of Albert O. Hirschman (Washington DC and Cambridge, MA: The Brookings Institution and The Lincoln Institute of Land Policy), pp. 277-283. 
Hirschman, Albert O., 1995a, "Preface," in Development Projects Observed, second edition (Washington, DC: Brookings Institution).

Hirschman, Albert O., 1995b, A Propensity to Self-Subversion (Cambridge, Mass.: Harvard University Press).

Hirschman, Albert O., 2015, Development Projects Observed, third edition published as a Brookings Classic with a new foreword by Cass R. Sunstein and a new afterword by Michele Alacevich (Washington, DC: Brookings Institution).

Klitgaard, Robert, 1997, "'Unanticipated Consequences' in Anti-Poverty Programs," World Development, vol. 25, no. 12 , pp. 1963-1972.

Kriz, Anton P., 2015, "Lessons about Transforming Regions: Not Simply 'Get Set, Go!'," paper presented at The XXVI ISPIM Conference: Shaping the Frontiers of Innovation Management, Budapest, Hungary, June 1417, pp. 1-16.

Krugman, Paul, 1994, "Krugman Discussion: Modeling, Learning, and Policy," in Appendix A of Lloyd Rodwin and Donald A. Schön, eds., Rethinking the Development Experience: Essays Provoked by the Work of Albert O. Hirschman (Washington DC and Cambridge, MA: The Brookings Institution and The Lincoln Institute of Land Policy), pp. 285-287.

Lal, Deepak, 1983, The Poverty of "Development Economics", second edition 1997, third edition 2002 (London: The Institute of Economic Affairs).

Lepenies, Philipp H., 2008, "Possibilism: An Approach to Problem-Solving Derived from the Life and Work of Albert O. Hirschman," Development and Change, vol. 39, no. 3, May, pp. 437-459.

Little, Ian M.D. and James A. Mirrlees, 1968, Manual of Industrial Project Analysis in Developing Countries (Paris: Development Centre of the OECD).

Marseille, Elliot, 1994, "Intraocular Lenses, Blindness Control, and the Hiding Hand," in Lloyd Rodwin and Donald A. Schön, eds., Rethinking the Development Experience: Essays Provoked by the Work of Albert O. Hirschman (Washington DC and Cambridge, MA: The Brookings Institution and The Lincoln Institute of Land Policy), pp. 147-175.

Millar, William W., 2005, "Demand Forecast Article Questionable," Letter to the Editor, Journal of the American Planning Association, vol. 71, no. 3, Summer 2005, p. 334. 
Offe, Claus, 2013, "Getting Ahead By Trespassing," review of Jeremy Adelman, Worldly Philosopher: The Odyssey of Albert O. Hirschman (Princeton, Princeton University Press 2013), European Journal of Sociology, vol. 54, pp. 583-591.

Picciotto, Robert, 1994a, "Visibility and Disappointment: The New Role of Development Evaluation," in Lloyd Rodwin and Donald A. Schön, eds., Rethinking the Development Experience: Essays Provoked by the Work of Albert O. Hirschman (Washington DC and Cambridge, MA: The Brookings Institution and The Lincoln Institute of Land Policy), pp. 210-230, 341-342.

Picciotto, Robert, 1994b, "Marseille Discussion: Learning via the Hiding Hand," in Appendix A of Lloyd Rodwin and Donald A. Schön, eds., Rethinking the Development Experience: Essays Provoked by the Work of Albert O. Hirschman (Washington DC and Cambridge, MA: The Brookings Institution and The Lincoln Institute of Land Policy), pp. 301-304.

Plummer, M., 2003, "JAGS: A Program for Analysis of Bayesian Graphical Models Using Gibbs Sampling," In Proceedings of the 3rd International Workshop on Distributed Statistical Computing.

Plummer, M., 2012, "rjags: Bayesian Graphical Models Using MCMC," R package version 3-7.

R Core Team, 2012, R: A Language and Environment for Statistical Computing (Vienna, Austria: R Foundation for Statistical Computing).

Reutlinger, Shlomo, 1970, Techniques for Project Appraisal under Uncertainty (Washington, DC: International Bank for Reconstruction and Development).

Rodwin, Lloyd, 1994, "Rethinking the Development Experience," in Lloyd Rodwin and Donald A. Schön, eds., Rethinking the Development Experience: Essays Provoked by the Work of Albert O. Hirschman (Washington DC and Cambridge, MA: The Brookings Institution and The Lincoln Institute of Land Policy), pp. 3-36.

Rodwin, Lloyd and Donald A. Schön, 1994, eds., Rethinking the Development Experience: Essays Provoked by the Work of Albert O. Hirschman (Washington DC and Cambridge, MA: The Brookings Institution and The Lincoln Institute of Land Policy).

Sandilands, Roger J., 2015, "The 1949 World Bank Mission to Columbia and the Competing Visions of Lauchlin Currie (1902-93) and Albert Hirschman (1915-2012)," History of Economic Thought and Policy, vol. 2015/1, issue 1, pp. 21-38. 
Sauer, Chris, Andrew Gemino, and Blaze Horner Reich, 2007, "The Impact of Size and Volatility on IT Project Performance," Communications of the ACM, vol. 50, no. 11, pp. 79-84.

Sawyer, John E., 2014, "Entrepreneurial Error and Economic Growth," originally published in Explorations in Entrepreneurial History, vol. IV:4, 1951-52, pp. 199-204, here from Bent Flyvbjerg, ed., Megaproject Planning and Management: Essential Readings, vol. I (Cheltenham, UK and Northampton, MA: Edward Elgar), pp. 143-148.

Schön, Donald A., 1994, "Hirschman's Elusive Theory of Social Learning," in Lloyd Rodwin and Donald A. Schön, eds., Rethinking the Development Experience: Essays Provoked by the Work of Albert O. Hirschman (Washington DC and Cambridge, MA: The Brookings Institution and The Lincoln Institute of Land Policy), pp. 67-95.

Squire, Lyn and Herman G. Van der Tak, 1975, Economic Analysis of Projects (Baltimore: The Johns Hopkins University Press).

Streeten, Paul P., 1984, "Comment," in Gerald M. Meier and Dudley Seers, eds., Pioneers in Development (New York: World Bank and Oxford University Press, pp. 115-18.

Sunstein, Cass R., 2013, "An Original Thinker of Our Time," The New York Review of Books, May 23, pp. 1417.

Sunstein, Cass R., 2015a, "Albert Hirschman's Hiding Hand," Foreword to Albert O. Hirschman, Development Projects Observed, third edition (Washington, DC: Brookings Institution).

Sunstein, Cass R., 2015b, personal communication, March 12, author's archives.

Tendler, Judith, 1994, "Taylor Discussion: Professional Practice, Modeling, Lore, and Prescription," in Appendix A of Lloyd Rodwin and Donald A. Schön, eds., Rethinking the Development Experience: Essays Provoked by the Work of Albert O. Hirschman (Washington DC and Cambridge, MA: The Brookings Institution and The Lincoln Institute of Land Policy), pp. 288-289. 
Table 1: Are higher-than-estimated costs outweighed by even higher-than-estimated benefits, as the Hiding Hand claims? The answer is a clear no; the Hiding Hand is rejected. (Cost and benefit overruns measured as actual divided by estimated costs and benefits [A/E], respectively, in real terms).

\begin{tabular}{|l|c|c|c|c|c|}
\hline \multicolumn{1}{|c|}{ Project type } & \multicolumn{2}{c|}{ Cost overrun } & \multicolumn{2}{c|}{ Benefit overrun } & $\mathbf{p}^{*}$ \\
\hline & $\mathbf{N}$ & Average cost overrun (A/E) & $\mathbf{N}$ & Average benefit overrun (A/E) & \\
\hline Dams & 243 & 1.96 & 84 & 0.89 & 0.0001 \\
\hline BRT $\dagger$ & 6 & 1.41 & 4 & 0.42 & 0.007 \\
\hline Rail & 264 & 1.40 & 74 & 0.66 & $<0.0001$ \\
\hline Tunnels & 48 & 1.36 & 23 & 0.81 & 0.015 \\
\hline Power plants & 100 & 1.36 & 23 & 0.94 & 0.0003 \\
\hline Buildings & 24 & 1.36 & 20 & 0.99 & 0.01 \\
\hline Bridges & 49 & 1.32 & 26 & 0.96 & $<0.0001$ \\
\hline Roads & 869 & 1.24 & 532 & 0.96 & $<0.0001$ \\
\hline Total & $\mathbf{1 6 0 3}$ & $\mathbf{1 . 3 9 / 1 . 4 3} \$$ & $\mathbf{7 8 6}$ & $\mathbf{0 . 9} / \mathbf{0 . 8 3} *$ & $<0.0001$ \\
\hline
\end{tabular}

*) The p-value of the test with null hypothesis that benefit overrun is actually larger than cost overrun, using Mann-Whitney

test (smaller p-values are better). †) Bus rapid transit. \$) Weighted and unweighted average, respectively. 
Figure 1: Box plots of cost risk and benefit risk 1920-2011; cost risk measured as cost overrun $(N=1271)$, benefit risk as benefit overrun $(N=625)$.

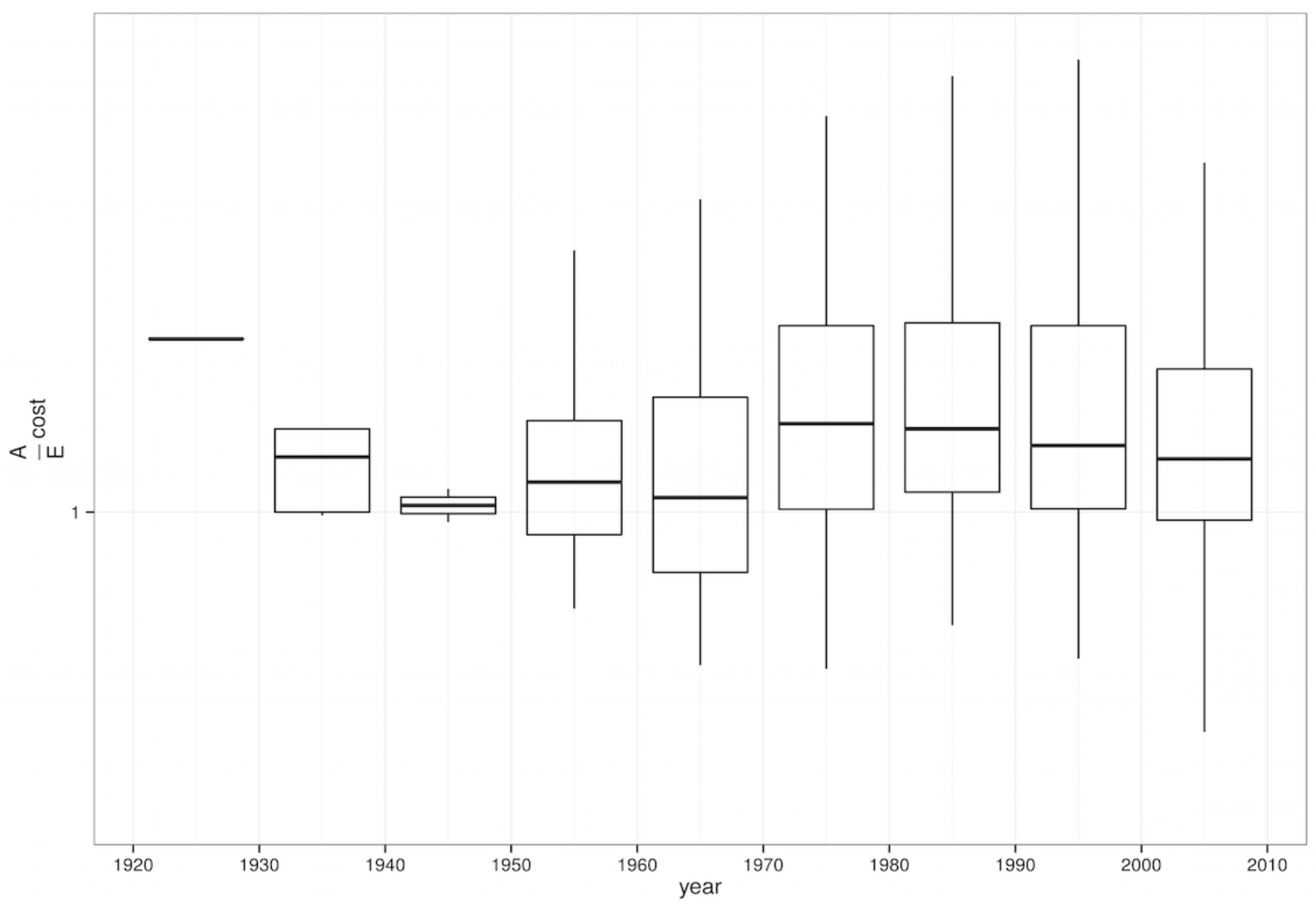




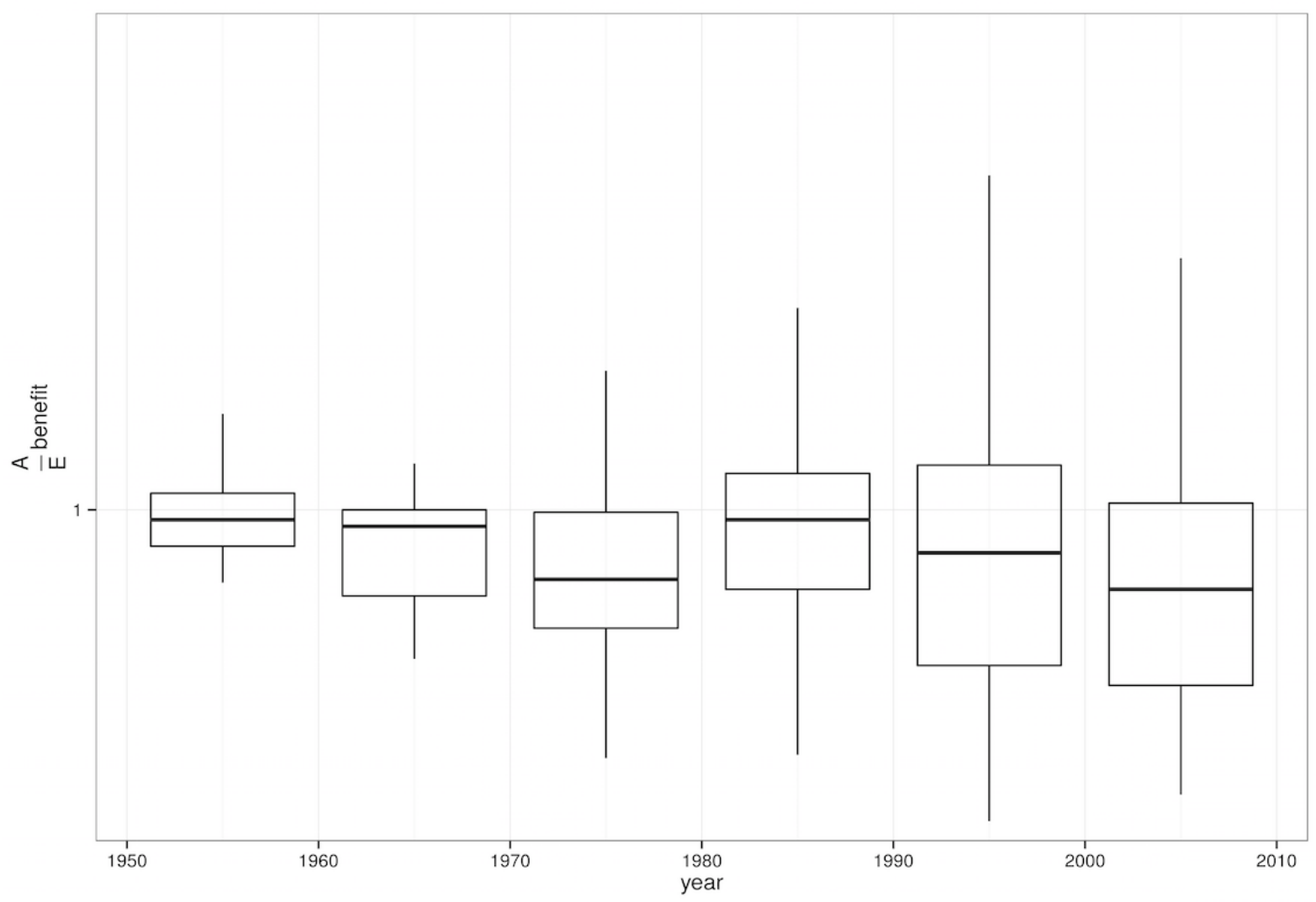




\section{Notes}

${ }^{1}$ The terms "principle" and "theory" are here used interchangeably. Later, we return to the question of whether the principle of the Hiding Hand is indeed a theory.

${ }^{2}$ For a recent academic endorsement of the principle of the Hiding Hand, see Kriz (2015: 14-15), who maintains, "Hirschman was right when he identified a 'hiding hand' ... [I]nterventions are ... probably best undertaken by people naïve about the full consequences of the risk." Similarly Lepenies (2008: 450) calls Development Projects Observed an "impressive analysis of development aid" with "explanations and analyses [that] are still valid today, including his [Hirschman's] 'Principle of the Hiding Hand' ... [T] he mere existence of the hiding hand is the reason why development projects are carried out in the first place."

${ }^{3}$ Gladwell (2013: 2) similarly calls Hirschman "one of the twentieth century's most extraordinary intellectuals."

${ }^{4}$ A new type of study of Hirschman's work by professional historians has begun to appear after the relevant archives have become accessible. Adelman (2013) is an example of this work as is Alacevich (2014). For the first time such material and studies are available for better understanding Hirschman. The present paper makes extensive use of these to help assess the validity of Hirschman's data and analyses. It is the first time the newly available archival material is used to systematically evaluate the Hiding Hand, or any of Hirschman's theories, to the knowledge of the author.

5 Two versions of Hirschman's classic text on the Hiding Hand exist (1967a, 1967b). The version cited here is the one published by the Brookings Institution in Development Projects Observed (Hirschman, 1967a), which is the original text. The other version is an article published by The Public Interest as "The Principle of the Hiding Hand." The differences between the two texts are minor and consist mainly in the article being less technical and more readable, with fewer caveats, than the book, due to editing by Irving Kristol, editor of The Public Interest at the time of publication (Adelman 2013: 405). Development Projects Observed was the third and culminating volume in a trilogy on development economics that also includes Hirschman $(1958,1963)$. The book was reissued in 1995 with a new preface by the author and reissued again in 2015 with a new foreword by Cass R. Sunstein and an afterword by Michele Alacevich. Sarah Hirschman, Albert O. Hirschman's wife, was a collaborator with her husband and did extensive work, in and out of the field, on the studies that led to the publications on the Hiding Hand (Adelman 2013: 388; Alacevich 2014: 149).

${ }^{6}$ It is interesting to note that the caveats included in Hirschman (1967a) were edited out in Hirschman (1967b). Because of its initial wider circulation as a journal article, Hirschman (1967b) came to dominate the reading of the Hiding Hand, and after its success the caveats, which had been weak to begin with, were quickly ignored, both by Hirschman and his readers.

${ }^{7}$ Even for IT projects, which are among the easiest type of project to abandon, and among the worst performing, the abandonment rate is estimated at only 9 percent (Sauer et al. 2007).

${ }^{8}$ Similarly, Hirschman's (1967b) Public Interest article on the Hiding Hand was recently included in a collection of "Essential Readings" in megaproject planning and management edited by the present author (Flyvbjerg 2014b). 
9 Jeremy Adelman and Cass Sunstein have both agreed to my use of their comments here.

${ }^{10}$ The term "theory" is here used to denote an idea, or a system of ideas, used to account for or explain a situation. This is similar to the way Hirschman uses the term.

${ }^{11}$ Hirschman (1967a: 3) used two criteria to select his small sample of World Bank projects: (a) the projects had to be well diversified as regards economic sector and geographical area, and (b) each project had to have an extended history, including several years of operations.

12 Adelman (2013: 392-393) further describes Hirschman's data collection as "hopeful"; it "resisted bleak conclusions, perhaps too obstinately" despite the fact that Hirschman's notes "are filled with the grouchy testimonies of his witnesses"; and it amounted to a "personal failure [on Hirschman's part] to see the disasters of development and evaluate them," according to Adelman.

${ }^{13}$ Lepenies (2008: 437) similarly observes, "work and life cannot be separated when discussing Hirschman."

${ }^{14}$ The closest we get to tests of the Hiding Hand are Cracknell (1984) and Picciotto (1994a). Cracknell, who was an officer with the UK Overseas Development Administration (ODA), wrote that data from 200 evaluations of ODA projects "lend little support" to the Hiding Hand (Cracknell 1984: 17-18), but unfortunately Cracknell did not present data or analyses to substantiate his claim. Picciotto, who was an officer with the World Bank, tried to evaluate the Hiding Hand, but the evaluation lacks rigor and good data and weakly concludes, "the hiding hand has its advantages as well as disadvantages" (Picciotto 1994a: 223).

${ }^{15}$ Only two of Hirschman's projects are non-infrastructure, namely an industry project (the Karnaphuli paper mill discussed in the main text) and a livestock project.

${ }^{16}$ It should be mentioned that sampling on the basis of data availability means that the results presented below are probably conservative, i.e., cost overruns and benefit shortfalls in the project population are most likely larger than in the sample. This is because availability of data is often an indication of better-than-average project management, and because data from badly performing projects are often not released. This must be kept in mind when interpreting the results from the statistical analyses, and it means that most likely the Hiding Hand is even more false in the project population than in the sample. For the full argument regarding the conservative bias in the data, see Flyvbjerg et al. (2002, 2005a) and Flyvbjerg (2005b).

${ }^{17}$ All statistical ideas and tools have limitations. In order to minimize bias caused by such limitations, the statistical tests used here were executed (i) using both conventional and Bayesian analysis, to test robustness of results across different statistical methods (ii) using two different samples, to test robustness across samples, (iii) comparing different geographies, to test robustness across space, and (iv) comparing different project types, to test robustness across sectors. For details of the different tests, please see main text.

${ }^{18}$ Estimated costs and benefits are the estimates made at the time of decision to build (final business case). Actual costs are measured as recorded outturn costs; actual benefits as first-year benefits, or a later value as close to this as possible, if 
available and if first-year benefits were not available. - First-year benefits may seem a narrow proxy to use for benefits, and it has been criticized as such. In fact, first-year benefits are a reliable measure, which is fortunate because the existence of benefits data for later years is so rare that benefits measurement would be rendered impossible for large samples if we had to rely on later-year data. For projects for which data are available on estimated and actual benefits covering more than one year after operations begin, it turns out that projects with lower-than-estimated benefits during the first year of operations also tend to have lower-than-estimated benefits in later years (Flyvbjerg 2013: 766-767). Using the first year as the basis for measuring benefits therefore appears not often to result in the error of identifying projects as underperforming in terms of benefits that would not be identified as such if a different time period were used as the basis for comparison. Actual benefits do not seem to quickly catch up with estimated benefits for projects with overestimated first-year benefits, and mostly they never do. Ramp up is assumed, but often does not happen, or happens only partly. To take a typical example, for the Channel tunnel between the UK and France, more than five years after opening to the public, train passengers numbered only 45 percent of that forecasted for the opening year; rail freight traffic was 40 percent of the forecast; and actual numbers have never caught up with the forecasts. - Using first-year benefits has also been criticized for not taking into account positive development effects, for instance increased real estate values following from improved transport services. Such effects undoubtedly exist, but if transport infrastructure has development benefits, these must be expected to be roughly proportional to traffic, so that if traffic has been overestimated, so must have the development benefits, which means that the case for proceeding with the project was exaggerated. The difference between estimated and actual traffic, including first-year patronage, would therefore be a good proxy for assessing the extent of the problem. The same applies to other types of infrastructure. For the full argument in this note and for further documentation, see Flyvbjerg (2005b; 2013).

19 Significance is here defined in the conventional manner, with $\mathrm{p} \leq 0.05$ being significant, $\mathrm{p} \leq 0.01$ very significant, and $\mathrm{p} \leq 0.001$ overwhelmingly significant.

${ }^{20}$ Ideally, data would be available for both cost overrun and benefit overrun for each project included in the statistical tests. However, data availability is far from ideal in the measurement of major project performance. For only 327 projects out of the 2,062 in the sample were data available for both cost overrun and benefit overrun. Using this ideal criterion would therefore result in scrapping large amounts of useful information for the 1,735 other projects in the sample, which would clearly be unacceptable. We therefore decided to run the statistical tests twice, first for the 2,062 projects in the total sample, and second for the subsample of 327 projects with data available for both cost overrun and benefit overrun.

${ }^{21}$ Average cost overrun for the subsample of 327 projects is 1.53 , average benefit overrun 0.89 (compared with 1.39 and 0.9 , respectively, for the larger sample). And again Hirschman's claim that benefit overruns are larger than cost overruns is rejected at the same overwhelmingly high level of statistical significance $(\mathrm{p}<0.0001$, paired Wilcoxon test). Finally, we tested results for the influence of project type and geography using Bayesian modeling. We found only few significant differences across project type and geography and none of them ran counter to the main conclusion above that higher-than-estimated 
costs are not outweighed by even higher-than-estimated benefits. This is unsurprising, given the overwhelmingly high level of statistical significance at which the main claim was rejected. Parameters for the models were estimated using MCMC. The language JAGS was used for this, through the rjags interface to R (Plummer 2003, 2012; R Core Team 2012). Statistical significance for the Bayesian tests was measured by the Bayes Factor (BF) instead of by p-values, where $12<\mathrm{BF} \leq 150$ indicates a statistically significant result and BF > 150 indicates a highly significant result.

${ }^{22}$ For more on the Malevolent Hiding Hand, see Flyvbjerg and Sunstein (in progress).

${ }^{23}$ The null hypothesis is: the net effect on benefits of the Benevolent Hiding Hand is equal to the net effect on costs of the Malevolent Hiding Hand; tested for the 327 projects with data for both cost overrun and benefit overrun.

${ }^{24}$ Marseille (1994) also describes a case where the Hiding Hand seems to apply.

${ }^{25}$ Hirschman is not alone in selecting data to make major project performance look better than it actually is. More recently, Millar (2005) did the same, as documented by Flyvbjerg et al. (2005b).

${ }^{26}$ This subsample is identical to the subsample of 327 projects used to test claim no. 1.

${ }^{27}$ Again, we tested for the influence of project type and geography using Bayesian modeling. Here we found statistical indication that cost overrun for dams have increased over time whereas cost overrun for rail has decreased; for the remaining six project types there was no statistically significant trend. For benefits, we found increasing overruns over time for power projects whereas overruns for roads were decreasing; again there was no statistically significant trend for the remaining six project types. Regarding geography, we found that cost overrun has increased over time in Latin America and North America, whereas cost overrun has decreased in Asia and Europe; for Africa and Oceania there were no statistically significant trends. For benefit overrun, we found decreasing overruns (increasing benefit shortfalls) for Asia and Latin America; there was no statistically significant trend for Africa, Europe, North America, and Oceania. We used the United Nation's macro-geographical (continental) regions as the basis for our geographical analyses (http://millenniumindicators.un.org/unsd/methods/m49/m49regin.htm). It should be mentioned that the differences between project types and geographies as regards change over time may be due to small numbers, especially for the early part of the period where observations are scant. Even if the dataset is the largest of its kind, when it is subdivided into eight project types, six regions, and up to nine time periods, some of the sub-samples become quite small and results correspondingly less reliable. But even with the small subsamples, when splitting by country and project type there is still a clear effect, which confirms just how strong that effect is.

${ }^{28}$ It is interesting to note that some of the projects Hirschman had originally described as successes in Development Projects Observed - projects he claimed in the book to have been saved by the Hiding Hand - actually turned out to be disasters. For instance, Hirschman's most prominent example in illustrating the Hiding Hand - the Karnaphuli paper mill, mentioned in the main text - turned a loss throughout the 1970's, becoming a drag on the national economy instead of the boost Hirschman had predicted just years before; the Paz del Rio steel mill in Colombia is another example of a major project admired by 
Hirschman where the Hiding Hand triggered financial disaster instead of creative solutions; and finally Nigeria's 300-mile Bornu railway catalyzed ethnic conflict that led to secession and a tragic civil war with hunger and starvation and killings in breakaway Biafra 1967-70 (Adelman 2013: 392; Alacevich 2007). According to Adelman (2013: 422), privately it disturbed Hirschman that he had failed to see that a project he had just studied could have such disastrous consequences so shortly after. But, curiously, nowhere does this failure, or the fact that project outcomes seemed to run counter to the principle of the Hiding Hand, cause Hirschman to critically assess and revise the principle, not even when he wrote a new Preface to a later edition of Development Projects Observed (Hirschman 1995a) or when a group of prominent scholars invited him to reflect on the principle (Rodwin and Schön 1994). 